\title{
PERANCANGAN APLIKASI BARANG MASUK DAN BARANG KELUAR PADA TOKO DIMAS JAYA BAN
}

\author{
Rini Hoirunnisa ${ }^{1}$, Forkas Tiroy Santos Butar-butar ${ }^{2}$, Ai Solihah ${ }^{3}$ \\ Program Studi Teknik Informatika, Fakultas Teknik dan Ilmu Komputer, \\ Universitas Indraprasta PGRI \\ Jalan Raya Tengah No 80, Kelurahan Gedong, Pasar Rebo, Jakarta Timur \\ rinihoirunnisa26@gmail.com ${ }^{1}$, fortysant.bb@gmail.com², faztasy@ yahoo.com ${ }^{3}$
}

\begin{abstract}
Abstrak
Dalam persaingan global saat ini teknologi informasi menjadi kebutuhan primer di segala bidang. Sebagai contoh nyata saat ini adalah teknologi pada sistem yang komputerisasi. Masalah yang dihadapi adalah bagaimana merancang suatu sistem informasi yang mencatat barang masuk dan barang keluar dengan detail dan rapih pada laporan. Tujuan dari penelitian adalah untuk mempermudah pekerjaan karyawan toko Dimas Jaya Ban Depok dalam mengelola data persediaan barang masuk dan barang keluar sehingga dapat terselesaikan secara lebih cepat, tepat dan efisien. Metode penelitian yang digunakan dalam mengembangkan sistem informasi adalah dengan pendekatan metode waterfall. Setelah dilakukan pengujian terhadap sistem, ditemukan bahwa sistem persediaan barang masuk dan barang keluar dapat memenuhi kebutuhan akan suatu proses pengolahan data yang cepat, akurat serta efektif dan efisien. Perancangan sistem informasi barang masuk dan barang keluar ini dibangun dengan menerapkan pemrograman JAVA berbasis Desktop yang dikembangkan menggunakan software NetBeans dan software XAMMP untuk mengelola database pada sistem.
\end{abstract}

Kata Kunci: Perancangan, Persediaan Barang Masuk dan Keluar, Java.

\begin{abstract}
In today's global competition, information technology has become a primary need in all fields. As a real example today is technology in computerized systems. The problem faced is how to design an information system that records incoming and outgoing goods in detail and neatly in the report. The purpose of this research is to facilitate the work of Dimas Jaya Ban Depok store employees in managing inventory data of incoming and outgoing goods so that they can be completed more quickly, precisely and efficiently. The research method used in developing information systems is the waterfall method approach. After testing the system, it was found that the incoming and outgoing goods inventory system can meet the need for a fast, accurate, effective and efficient data processing process. The design of the incoming and outgoing goods information system was built by implementing Desktop-based JAVA programming which was developed using NetBeans software and XAMMP software to manage databases on the system.
\end{abstract}

Keywords :Design, In and Out Goods Inventory, Java.

\section{PENDAHULUAN}

Perkembangan teknologi yang cukup pesat dari waktu ke waktu membuat pekerjaan yang dilakukan manusia pada umumnya dapat diselesaikan dengan cepat. Di era globalisasi seperti sekarang ini, teknologi menjadi kebutuhan primer di segala bidang. Sebagai contoh nyata saat ini adalah penggunaan komputer. Sehingga pada saat ini semua elemen masyarakat memanfaatkan komputer ke segala bidang, salah satunya adalah dalam bidang ekonomi dan bisnis.

Toko Dimas Jaya Ban merupakan salah satu perusahaan yang bergerak dibidang penjualan yang berlokasi di Depok, merupakan salah satu perusahaan yang sedang berkembang dan terus berupaya meningkatkan kinerja pelayanan terhadap konsumen. Perusahaan ini memiliki pelanggan yang cukup besar. Dimana pengolahan data-data yang cukup banyak akan membutuhkan tempat penyimpanan data dalam kapasitas yang cukup besar. Laporan-laporan data hasil persediaan barang akan membutuhkan waktu yang lama jika menggunakan sistem yang masih manual karena pembuatan data-data yang masih tersimpan dalam file-file yang tersusun dalam arsip hasil ketersediaan barang. Penggunaan komputer dalam mengatasi masalah seperti di atas memberikan 
manfaat dan kontribusi terhadap pemecahanan masalah sehingga data akan tersimpan dengan aman dapat diolah dengan nyaman. Menurut (Rizky, 2011), perancangan adalah sebuah proses untuk mendefinisikan sesuatu yang akan dikerjakan dengan menggunakan teknik yang bervariasi serta didalamnya melibatkan deskripsi mengenai arsitektur serta detail mengenai komponen dan juga keterbatasan yang akan dialami dalam proses pengerjaannya. Tujuan penelitian ini adalah untuk membuat aplikasi yang dapat memudahkan karyawan toko dalam perhitungan data persediaan barang agar laporan yang dibutuhkan bisa cepat diterima.

\section{PENELITIAN RELEVAN}

Untuk menciptakan sistem informasi barang masuk dan barang keluar, peneliti mendapatkan referensi penelitian dari jurnal yang berjudul "Perancangan Sistem Informasi Persediaan Barang (Studi Kasus : Universitas Stikubank Semarang)” yang membahas tentang sistem persediaan alat tulis kantor yang dibutuhkan bila ada suatu kegiatan di Universitas Stikubank Semarang dan pada akhirnya nanti bisa membuat suatu laporan yang dapat digunakan untuk evalusi pada waktu-waktu yang akan datang bila ada kegiatan di Universitas Stikubank Semarang. (Munawaroh, 2006). Dan artikel yang berjudul "Sistem Informasi Inventori Barang Pada CV. Putra Karya Baja Dengan Metode Waterfall", disusun oleh (Nurfi, 2020) sebagai solusi mengatasi permasalahan dalam pengolahan data yang masih manual menjadi terkomputerisasi. Dengan begitu sistem ini diharapkan mampu meningkatkan kinerja karyawan dalam pengolahan data menjadi lebih cepat, tepat dan efisien.. Dari jurnal tersebut terdapat kesamaan yaitu tentang bagaimana merancang suatu sistem informasi persediaan barang untuk sebuah laporan yang detail.

\section{METODE PENELITIAN}

Dalam melakukan penelitian senantiasa diperlukan suatu metode penelitian yang sesuai dengan pokok permasalahan yang akan diteliti. Menurut (Sugiyono, 2009), metode penelitian yaitu cara ilmiah untuk mendapatkan data yang valid dengan tujuan dapat ditemukan, dikembangkan dan dibutuhkan suatu pengetahuan tertentu sehingga pada gilirannya dapat digunakan untuk memahami, memecahkan dan mengantisipasi masalah dalam bidang bisnis.

Dalam penelitian ini, metode pengumpulan data yang dilakukan dengan cara pengumpulan bahanbahan keterangan juga data yang berhubungan dengan judul penelitian ini, sehingga tidak menyimpang dari pokok permasalahan. Adapun metode yang digunakan adalah:

Observasi yaitu mengenai proses pendataan barang-barang yang ada di dalam toko, data-data yang dijual yang ada dalam toko dan pendataan barang-barang yang baru diterima dari supplier. (Mardalius, 2013)

Wawancara yaitu melakukan pengumpulan data dengan melakukan tanya jawab dan tinjauan langsung dengan pemilik toko Dimas Jaya Ban mengenai hal yang berhubungan dengan penelitian ini. (Efriyanti et al., 2018)

Studi Pustaka yaitu mengumpulkan data dan mempelajari atau membaca pendapat ahli yang berhubungan dengan permasalahan yang akan diteliti untuk memperoleh data yang diperlukan, serta untuk landasan teori yang akurat dan menunjang. (Hasyim, W., \& Suryadi, 2021)

Metode yang digunakan untuk pengembangan sistem adalah dengan metode SDLC, yaitu waterfall model. Model air terjun (waterfall) menyediakan pendekatan alur hidup perangkat lunak secara sekuensial atau terurut dimulai dari analisis, desain, pengodean, pengujian, dan tahap pendukung (support). (Nur, 2019). Metode pengembangan sistem yang digunakan adalah metode Waterfall, dengan tahapan sebagai berikut : 


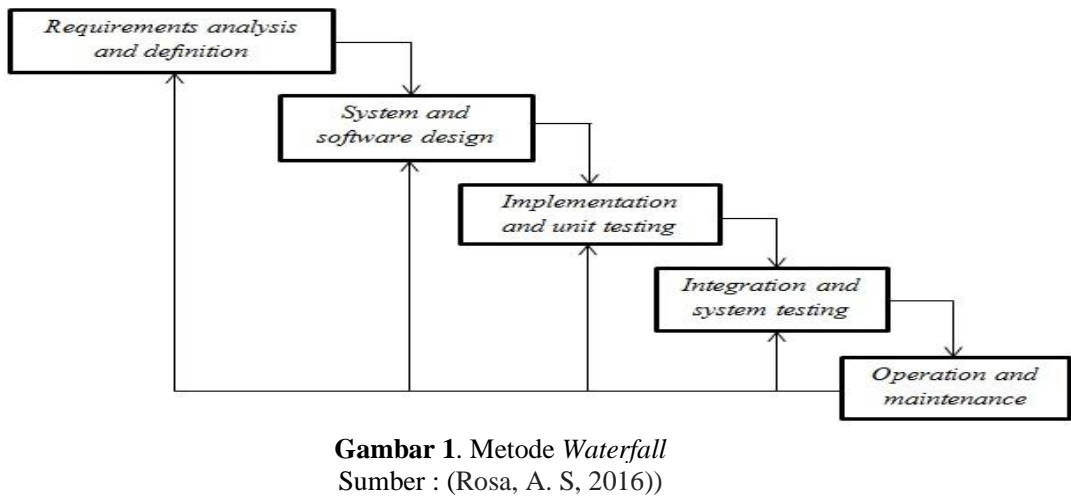

Berikut ini adalah penjelasan dari tahap-tahap yang terdapat dalam metode Waterfall :

Requirements analysis and definition

Mengumpulkan kebutuhan secara lengkap kemudian dianalisis terhadap permasalahan yang dihadapi dan menetapkan kebutuhan perangkat untuk bisa menghasilkan desain yang lengkap.

System and software design

Desain dikerjakan setelah kebutuhan selesai dikumpulkan secara lengkap untuk perangkat lunak, fungsi dan interfacing.

Implementation and unit testing

Desain program diterjemahkan ke dalam kode atau bahasa yang dimengerti oleh mesin komputer dengan menggunakan bahasa pemrograman yang sudah ditentukan. Program yang dibangun langsung diuji baik secara unit.

Integration and system testing

Kegiatan untuk melakukan pengetesan program yang sudah dibuat apakah sudah benar atau belum kemudian setiap unit disatukan dan diuji secara keseluruhan (system testing).

Operation and maintenance

Mengoperasikan program dilingkungannya dan melakukan pemeliharaan, seperti penyesuaian atau perubahan karena adaptasi dengan situasi sebenarnya.

\section{HASIL DAN PEMBAHASAN}

\section{Analisis Permasalahan}

Kekurangan yang terdapat pada sistem yang sedang berjalan adalah sebagai berikut :

1. Penulisan data barang masih dilakukan secara manual.

2. Proses pencatatan secara konvensional memerlukan tempat penyimpanan yang sangat luas, dokumen yang bertumpuk yang memerlukan waktu yang lama dalam proses pencarian data.

3. Kontrol terhadap data barang menjadi tidak efisien karena sering terjadi kesalahan dalam proses pencarian data dalam berkas yang bertumpuk.

4. Laporan barang pada took yang dilakukan secara manual memungkinkan kesalahan data dan memerlukan waktu ekstra dalam mengubah data tersebut.

\section{Alternatif Penyelesaian Masalah}

Menurut (Jogiyanto, 2005) analisis sistem sebagai penguraian dari suatu sistem informasi yang utuh ke dalam bagian-bagian komponennya agar dapat mengidentifikasikan dan mengevaluasi permasalahan dan kesempatan. Berdasarkan analisis permasalahan diatas dapat disimpulkan bahwa perlu diadakannya perbaikan sistem berupa pembangunan program aplikasi yang dapat menampilkan informasi. Sehingga proses pengolahan data dan pencarian data yang dibutuhkan lebih cepat, efektif, efisien dan akurat.

\section{Diagram Konteks}

Berikut ini merupakan gambaran tentang sistem yang diusulkan pada pengolahan data persediaan barang masuk dan barang keluar pada Toko Dimas Jaya Ban Depok : 
Jurnal Riset dan Aplikasi Mahasiswa Informatika (JRAMI)

Vol QZ No Q3 Tahun 202I

e-ISSN : $2715-8756$

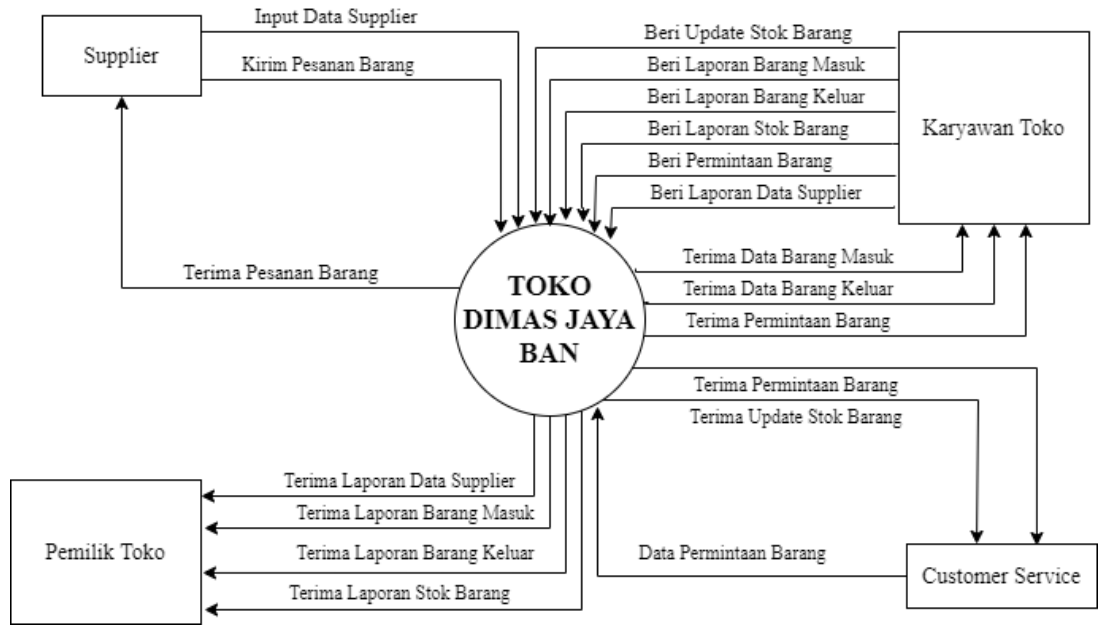

Gambar 2. Diagram Konteks Sistem Yang Diusulkan

\section{Entity Relation Diagram (ERD)}

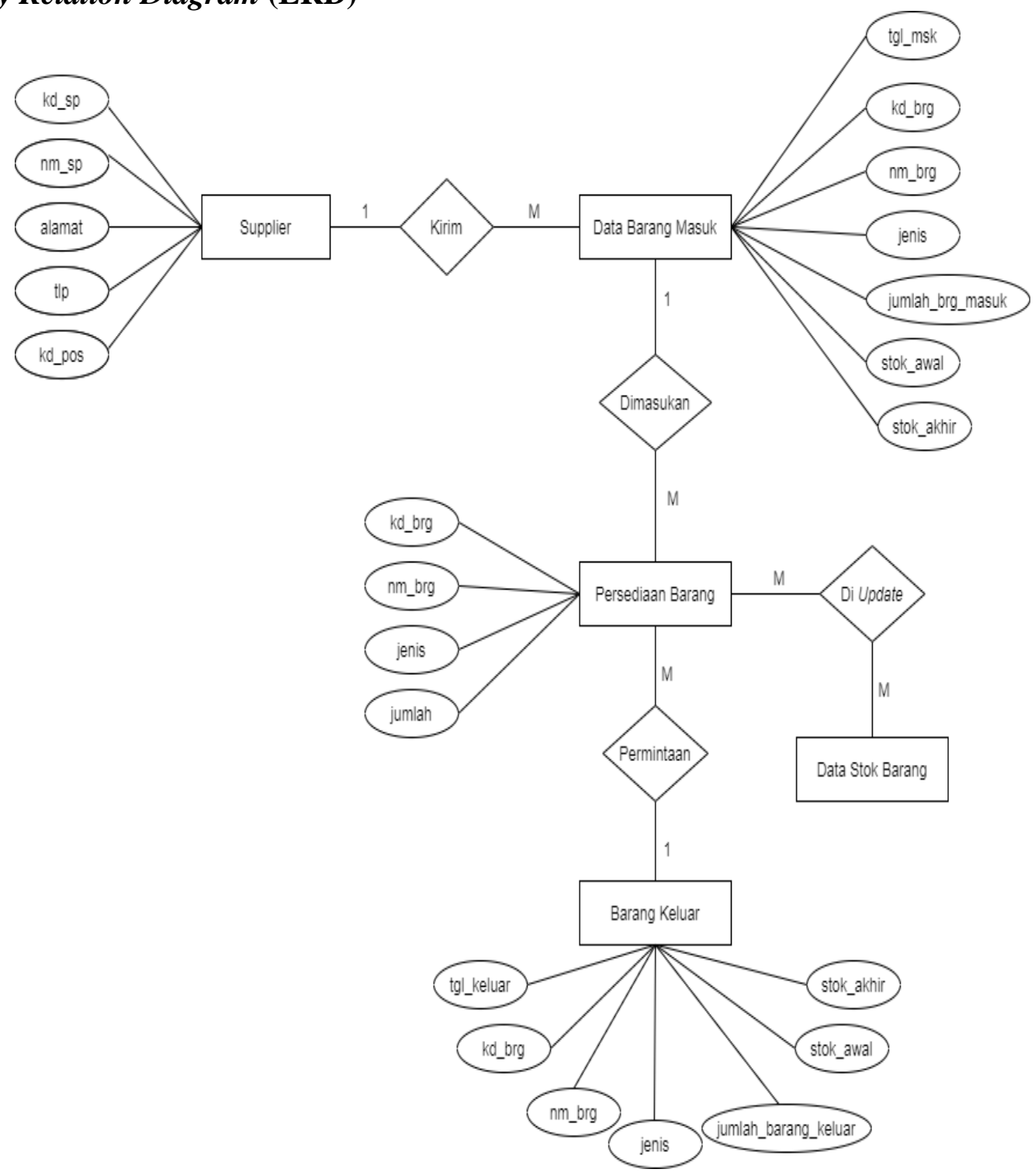

Gambar 3. Entity Rational Diagram (ERD) 


\section{Tampilan Layar}

Tampilan Layar Menu Login

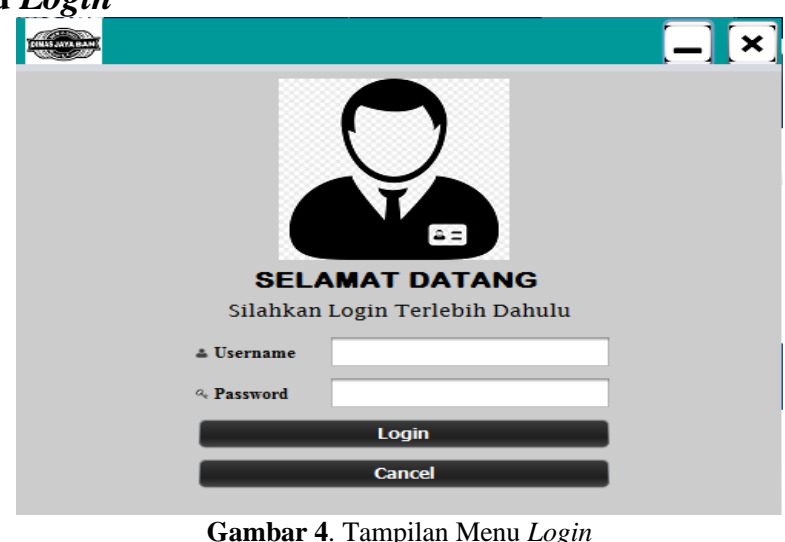

Tampilan awal program aplikasi persediaan barang masuk dan barang keluar. Memasukkan User dan Password untuk dapat mengakses aplikasi persediaan barang masuk dan barang keluar.

\section{Tampilan Layar Menu Utama}

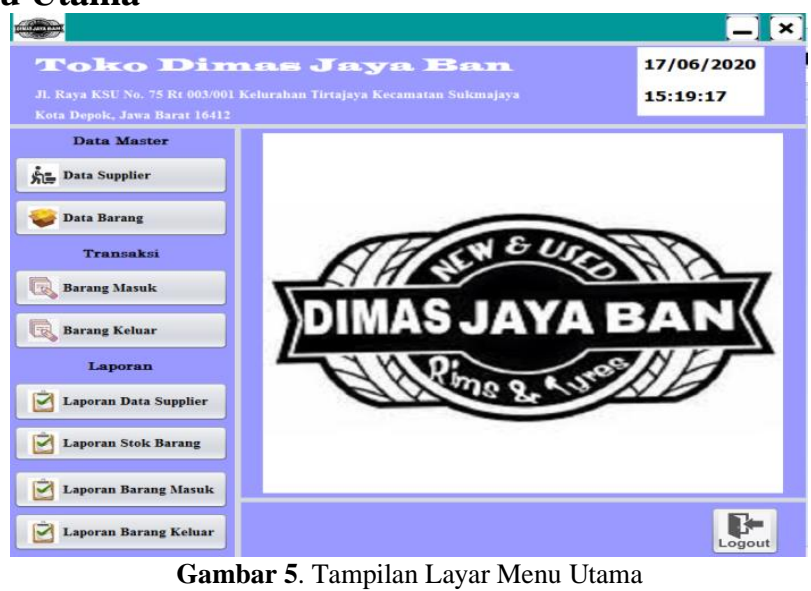

Tampilan layar menu utama, berfungsi untuk mempermudah user mengisi data barang masuk, barang keluar, stok barang, data supplier, serta laporan.

\section{Tampilan Form Input Data Supplier}

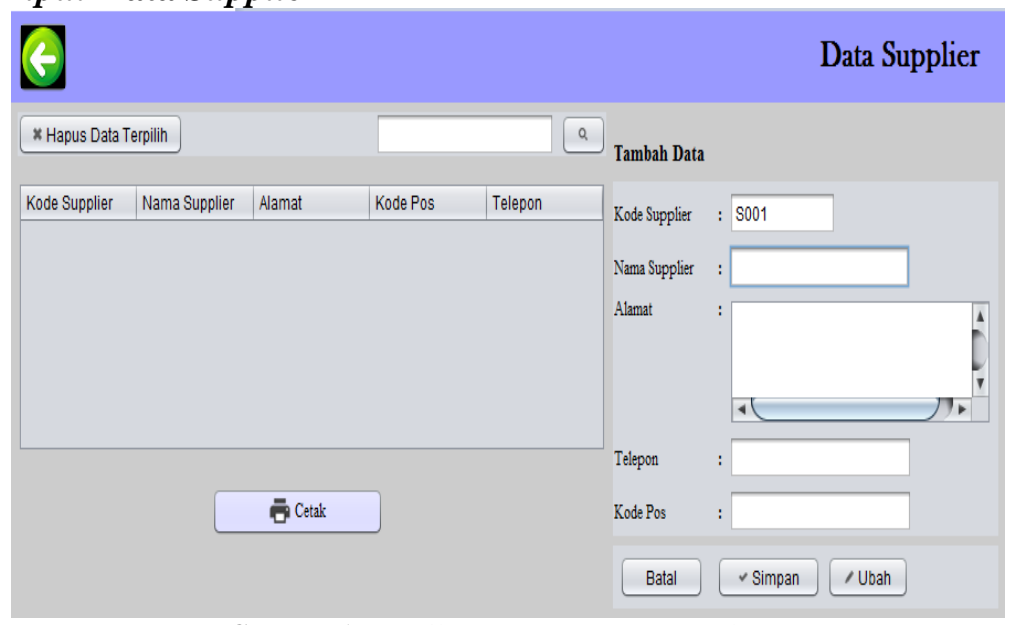

Gambar 6. Tampilan Form Input Data Supplier

Pada form data supplier ini, user melakukan pengisian data supplier dengan menggunakan kode supplier, nama supplier, alamat, telepon dan kode pos. 


\section{Tampilan Form Input Data Barang}

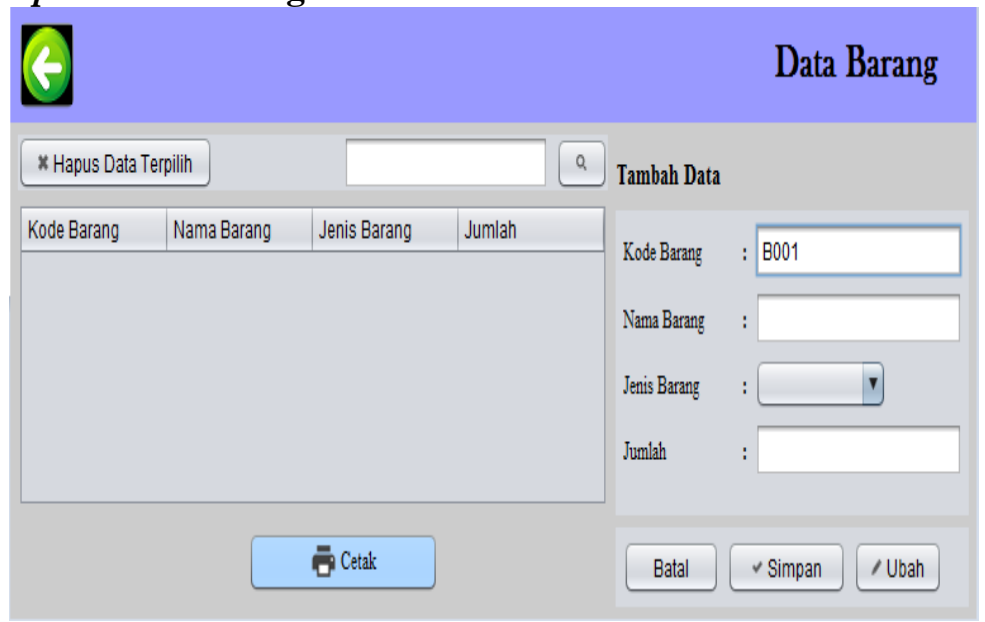

Gambar 7. Tampilan Form Input Data Barang

Pada form data barang, user melakukan pengisian data dengan menggunakan kode barang, nama barang, jenis barang dan jumlah.

\section{Tampilan Form Input Data Barang Masuk}

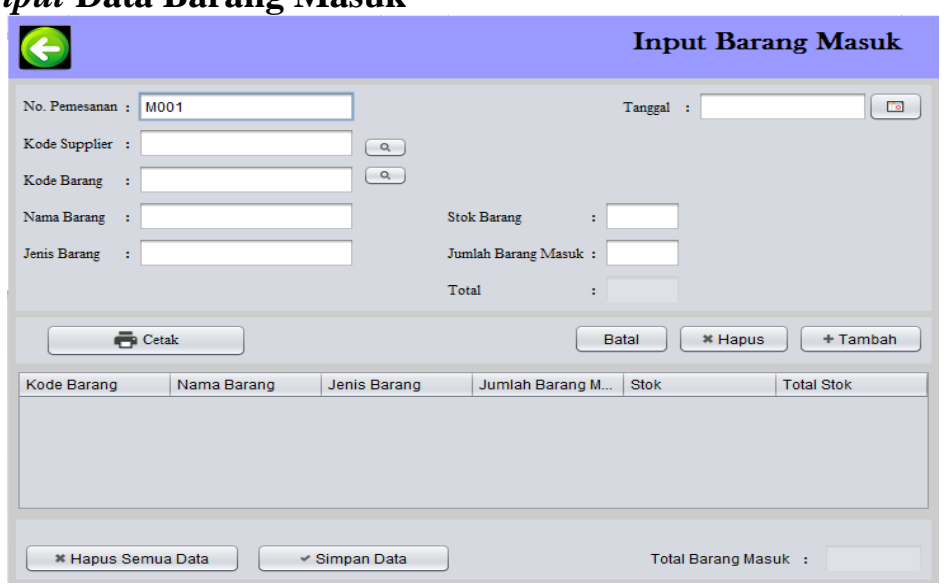

Gambar 8. Tampilan Form Input Data Barang Masuk

Pada form data barang masuk, user melakukan pengisian data dengan menggunakan tanggal, no.Pemesanan, kode supplier, kode barang, nama barang, jenis barang, stok barang, jumlah barang masuk, total stok.

\section{Tampilan Form Input Data Barang Keluar}

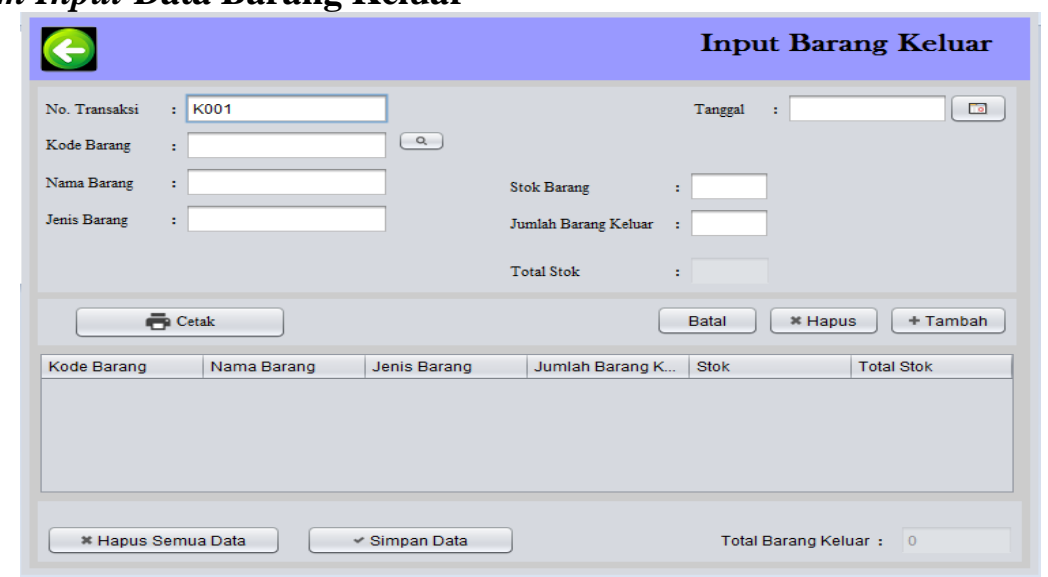

Gambar 9. Tampilan Form Input Data Barang Keluar 
Pada form data barang keluar, user melakukan pengisian data dengan menggunakan tanggal, no. Transaksi, kode barang, nama barang, jenis barang, stok barang, jumlah barang keluar, total stok.

\section{Tampilan Cetak Laporan Data Supplier}

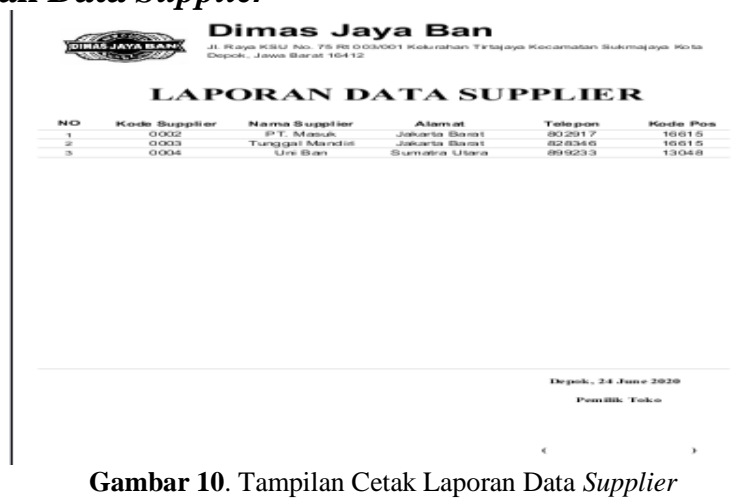

\section{Tampilan Cetak Laporan Data Stok Barang}
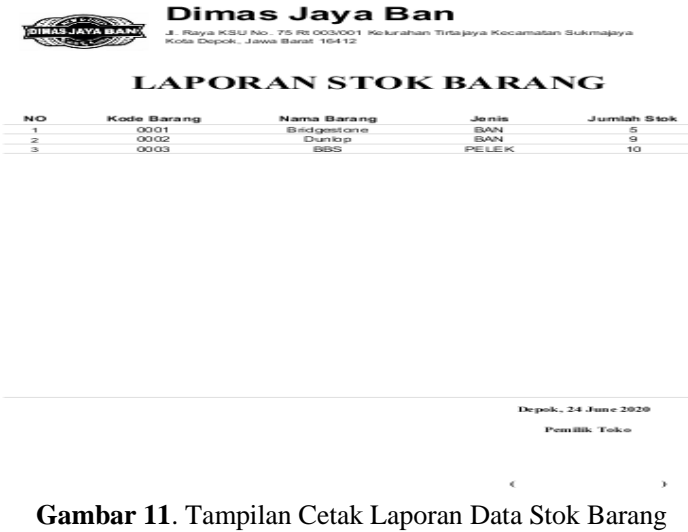

Tampilan Cetak Laporan Data Barang Masuk

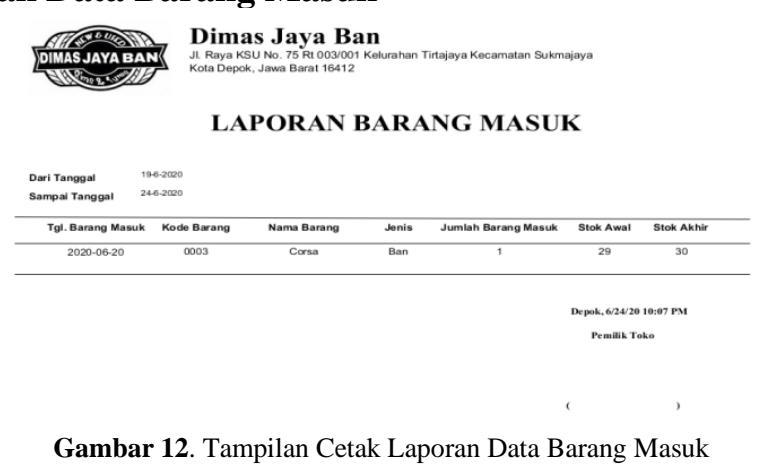

Tampilan Cetak Laporan Data Barang Keluar

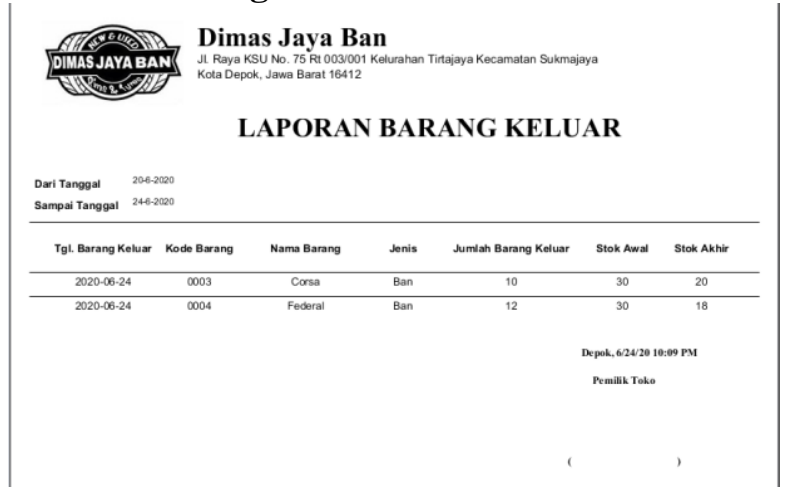

Gambar 13. Tampilan Cetak Laporan Data Barang Keluar 


\section{SIMPULAN}

Dari hasil penelitian dapat disimpulkan bahwa sistem pengolahan data persediaan barang menggunakan sistem manual yang membutuhkan waktu yang cukup lama dalam mengolah data serta penyimpanan data. Sedangkan penggunaan sistem yang baru dengan berbasis sistem komputer khususnya dengan sistem informasi persediaan barang menggunakan java, diharapkan informasi yang dihasilkan dalam pembuatan sistem informasi pengolahan data barang bisa lebih cepat dan mengurangi kesalahan dalam proses penginputan data. Karena sistem yang komputerisasi mempunyai banyak keuntungan, terutama dalam hal pengolahan data.

\section{DAFTAR PUSTAKA}

Efriyanti, M., Garaika, R. I., \& Irviani, R. (2018). Analisis Implementasi Electronic Commerce Untuk Meningkatkan Omset Penjualan Butik Mery Berbasis Web Mobile. Jurnal Signaling, 7(2), 45-51.

Hasyim, W., \& Suryadi, A. (2021, January). Sistem Informasi Persediaan Dan Pendistribusian Kartu ATM Pada Bank Syariah Mandiri. In Semnas Ristek (Seminar Nasional Riset dan Inovasi Teknologi) (Vol. 5, No. 1).

Jogiyanto, H. M. (2005). Analisis \& Desain Sistem Informasi. Yogjakarta: Andi Offset.

Mardalius, M. (2018). Perancangan Dan Implementasi Point Of Sale System Menggunakan Bahasa Pemprograman Visual Basic. Net 2013 Dan Database Sql Server 2012 Pada Toko Rafadel.

Munawaroh, S. (2006). Perancangan Sistem Informasi Persediaan Barang. Dinamik, 11(2).

Nur, H. (2019). Penggunaan Metode Waterfall Dalam Rancang Bangun Sistem Informasi Penjualan. Generation Journal, 3(1), 1-10.

Nurfi, S. (2020). Sistem Informasi Inventori Barang Pada CV. Putra Karya Baja Dengan Metode Waterfall. BINA INSANI ICT JOURNAL, 7(2), 145-155.

Rosa, A. S. (2016). Rekayasa Perangkat Lunak Terstruktur Dan Berorientasi Objek.

Rizky, S. (2011). Konsep Dasar Rekayasa Perangkat Lunak. Yogyakarta: PT. Prestasi Pustakarya.

Sugiyono, M. P. P., \& Kuantitatif, P. (2009). Kualitatif, dan R\&D, Bandung: Alfabeta. Cet. VII. 